\title{
A multicenter, randomized, controlled trial of rebamipide plus lansoprazole for the treatment of post-endoscopic submucosal dissection ulcers
}

\author{
Bin Yan ${ }^{1, *}$, Zhongsheng $\mathrm{Lu}^{1, *}$, Zhizheng $\mathrm{Ge}^{2}$, Side $\mathrm{Liu}^{3}$, Xuegang $\mathrm{Guo}^{4}$, Dean Tian ${ }^{5}$, \\ Yuxiu Yang ${ }^{6}$, Xiaobo Li ${ }^{2}$, Wei Gong ${ }^{3}$, Zhiguo Liu ${ }^{4}$, Mei Liü ${ }^{5}$, Bingxi Zhou ${ }^{6}$, Kabing Zhao ${ }^{1}$, \\ Jing Yang ${ }^{1}$ and Yunsheng Yang ${ }^{1}$ \\ ${ }^{1}$ Department of Gastroenterology and Hepatology, Chinese PLA General Hospital, Beijing, China \\ ${ }^{2}$ Department of Gastroenterology and Hepatology, Renji Hospital, Shanghai, China \\ ${ }^{3}$ Department of Gastroenterology and Hepatology, Nanfang Hospital, Guangzhou, Guangdong Province, China \\ ${ }^{4}$ Department of Gastroenterology and Hepatology, Xijing Hospital, Xian, Shanxi province, China \\ ${ }^{5}$ Department of Gastroenterology and Hepatology, Tongji Hospital, Wuhan, Hubei province, China \\ ${ }^{6}$ Department of Gastroenterology and Hepatology, Henan Provincial People's Hospital, Zhengzhou, Henan Province, China \\ *These authors contributed equally to this work
}

Correspondence to: Yunsheng Yang, email: sunny301ddc@126.com

Keywords: randomized clinical trial; endoscopic submucosal dissection; ulcer; lansoprazole; rebamipide

Received: September 29, 2017 Accepted: November 15, $2017 \quad$ Published: January 02, 2018

Copyright: Yan et al. This is an open-access article distributed under the terms of the Creative Commons Attribution License 3.0 (CC BY 3.0 ), which permits unrestricted use, distribution, and reproduction in any medium, provided the original author and source are credited.

\section{ABSTRACT}

Objective: To evaluate the healing efficacy of rebamipide and lansoprazole combination therapy with lansoprazole alone for endoscopic submucosal dissection (ESD)-induced ulcers and clarify the ulcer healing-associated factors.

Materials and Methods: Three hundred patients were randomized into control and experimental groups after undergoing ESD. The patients received intravenous pantoprazole (30 mg) every 12 hours and oral rebamipide (100 mg, experimental group) or placebo (control group) three times daily on days 1-3. On days 4-56, patients received oral lansoprazole (30 $\mathrm{mg}$ daily) and rebamipide $(100 \mathrm{mg}$ ) or placebo three times daily. Endoscopic evaluations were performed at postoperative 4 and 8 weeks.

Results: At week 4, the ulcer reduction rate was significantly higher in the experimental than in the control group $(0.94 \pm 0.078$ vs. $0.97 \pm 0.034 ; P<0.001)$. The ulcer healing $(20.3 \%$ vs $18.2 \% ; P=0.669)$ and ulcer improvement rates $(88.7 \%$ vs $94.2 \% ; P=0.109$ ) in the two groups were not significantly different. At week 8 , the ulcer healing and ulcer improvement rates were $90.6 \%$ and $100 \%$, respectively, in both groups. Multivariate analysis showed that the combination treatment was an independent factor associated with ulcer area reduction after ESD. The maximum diameter of the initial ulcer ( $\geq 35.5 \mathrm{~mm}$ vs. $<35.5 \mathrm{~mm}$ ) was an independent factor associated with the ulcer improvement rate after ESD.

Conclusions: The rebamipide and lansoprazole combination therapy can help accelerate the reduction rate of post-ESD ulcer compared with the lansoprazole monotherapy at four weeks of therapy.

\section{INTRODUCTION}

Endoscopic submucosal dissection (ESD), developed in Japan in the 1990s [1, 2], is currently a widely accepted treatment for early gastric mucosal lesions as it is minimally invasive and enables the en bloc resection of mucosal lesions [3]. Due to the widespread use of endoscopy and the higher rate of early lesion detection, the application of ESD has become increasingly common. This trend has been accompanied by increasing concern about ESD 
complications. These procedures sometimes lead to deep and large gastrointestinal ulcers, resulting in an increased risk of perforation, bleeding, and abdominal pain $[4,5]$. The management of giant ulcers induced by ESD is a challenge and, hence, has become a focus of clinical research $[6,7]$.

Currently, there is no standardized regimen for the treatment of gastric giant ulcers induced by ESD, but proton pump inhibitors (PPIs) are still commonly used with 8 weeks for this purpose. Nevertheless, rebamipide has been evaluated for the treatment of post-ESD ulcers, and its clinical efficacy has been verified by numerous investigators [8]. Effective treatment regimens for post-ESD ulcers might involve rebamipide alone or in combination with PPIs. Some studies have indicated that the clinical efficacy of rebamipide alone is similar, or even superior, to that of PPIs alone [9]. Others have shown that rebamipide combined with PPIs can accelerate the healing of ulcers compared to monotherapy using PPIs [10-12]. Given this, the present study was to determine whether PPIs combined with rebamipide would promote post-ESD ulcer healing more effectively than PPIs alone and explore the ulcer healing-associated factors.

\section{RESULTS}

\section{Characteristics of research subjects}

Among the 300 subjects, 318 lesions were removed by ESD (due to statistical requirements, if a patient had multiple resected lesions, the healing of only one was assessed). We evaluated 133 control group patients at the four-week follow-up. Four control cases were excluded as they required additional surgery to treat residual marginal disease, ten were excluded due to bleeding that required repeat endoscopic treatment, and three cases were lost to follow-up. We assessed 137 experimental group patients at the four-week follow-up. Three cases were excluded as they required additional surgery, six were excluded due to bleeding that required repeat endoscopic treatment, and four were lost to follow-up. In each group (experimental and control), 127 patients completed eight weeks of treatment observation (six control group and ten experimental group cases were lost to follow-up). Details of the experimental procedure are shown in Figure 1. The characteristics of the research subjects in both groups were shown in Table 1. Our analysis demonstrated no statistically significant differences in the gender, age, body mass index (BMI), comorbidities, presence of Helicobacter pylori (Hp) infection, lesion pathological features or anatomical location, initial size of the post-ESD ulcer, or maximum or perpendicular diameter of the ulcer between the groups.

\section{Outcomes of ulcer healing after combination therapy and monotherapy}

The primary outcomes of ulcer healing after combination therapy and monotherapy were the ulcer reduction rates at four weeks of treatment. As shown in Table 1, the ulcer reduction rate was significantly higher in the experimental group than that in the control group after four weeks of treatment $(97 \%$ vs. $94 \%, P<0.001)$. The secondary outcomes were the healing rate, the improvement rate, ulcer area, maximum diameter, and perpendicular diameter after four weeks of treatment or eight weeks of treatment, which were also summarized in Table 1. After four weeks of treatment, the experimental group showed a post-ESD ulcer healing rate of $18.2 \%$ and an improvement rate of $94.2 \%$ while the control group showed a post-ESD ulcer healing rate of $20.3 \%$, and an improvement rate of $88.7 \%$. The healing rate and improvement rate of post-ESD ulcers did not show statistically significant differences between the two drug regimens $(P>0.05)$. Moreover, at four weeks of treatment, the differences between the experimental group and control group in terms of ulcer area $\left(36.35 \pm 51.36 \mathrm{~mm}^{2}\right.$ vs. $\left.55.04 \pm 67.56 \mathrm{~mm}^{2}\right)$, maximum diameter $(6.30 \pm 5.05$ $\mathrm{mm}$ vs. $7.80 \pm 5.96 \mathrm{~mm}$ ), and perpendicular diameter $(3.55 \pm 3.18 \mathrm{~mm}$ vs. $4.74 \pm 3.64 \mathrm{~mm})$ were statistically significant $(P=0.011, P=0.027, P=0.004$, respectively). At eight weeks, the ulcer healing rate in both groups was $90.6 \%$, and the ulcer improvement rate in both groups was 100\% (Table 2).

\section{Subgroup analysis of factors influencing ulcer reduction post-ESD}

Subgroup analysis was performed to investigate the factors affecting the efficacy of rebamipide plus lansoprazole for post-ESD ulcer reduction at four weeks (Table 3). For factors recorded as numerical data, the group's mean value was used to determine thresholds for age (60 years), BMI (23.22), initial ulcer area (1084.45 $\mathrm{mm}^{2}$, initial maximum diameter $(35.50 \mathrm{~mm})$, and initial perpendicular diameter $(27.29 \mathrm{~mm})$ that defined two factor-based subgroups. For qualitative factors, patients were divided into subgroups based on existing categories or the presence or absence of the factor. The results indicated that the subgroup factors related to ulcer healing included: patient age and BMI; initial ulcer area, maximum diameter, and perpendicular diameter; lesion site and pathological grade; and the presence of underlying disease or Hp infection.

\section{Logistic regression analysis of factors influencing post-ESD ulcer reduction}

Univariate and multivariate logistic regression models were used to analyze the factors influencing ulcer reduction at four weeks. The results are shown in Table 4. The dependent variable was a post-ESD ulcer reduction. Moreover, the mean ulcer reduction rate defines the cutoff value of the variable ( $\geq 95 \%$ vs. $<95 \%$ ). The independent variables were the relevant variables determined by our 
Table 1: Characteristics of subjects and lesions

\begin{tabular}{|c|c|c|c|}
\hline Characteristics & Control group $n=150$ & Experimental group $n=150$ & $P$-value \\
\hline Gender (male/female) & $106 / 44$ & $103 / 47$ & 0.706 \\
\hline Age $($ mean $\pm \mathrm{SD})$ & $59.95 \pm 10.10$ & $59.80 \pm 10.09$ & 0.900 \\
\hline $\mathrm{BMI}($ mean $\pm \mathrm{SD})$ & $23.26 \pm 2.94$ & $23.24 \pm 3.18$ & 0.954 \\
\hline Pathological grade: $n(\%)$ & & & 0.567 \\
\hline Cancer & $9(6.0 \%)$ & $14(9.3 \%)$ & \\
\hline HIN & $81(54.0 \%)$ & $75(50.0 \%)$ & \\
\hline LIN & $36(24 \%)$ & $32(21.3 \%)$ & \\
\hline Others & $24(16.0 \%)$ & $29(19.3 \%)$ & \\
\hline Lesion site: $n(\%)$ & & & 0.944 \\
\hline Gastric antrum & $77(51.3 \%)$ & $80(53.3 \%)$ & \\
\hline Angular incisure & $27(18.0 \%)$ & $28(18.7 \%)$ & \\
\hline Distal gastric body & $10(6.7 \%)$ & $11(7.3 \%)$ & \\
\hline Proximal gastric body & $10(6.7 \%)$ & $6(4.0 \%)$ & \\
\hline Gastric fundus & $6(4.0 \%)$ & $5(3.3 \%)$ & \\
\hline Gastric cardia & $20(13.3 \%)$ & $20(13.3 \%)$ & \\
\hline Underlying disease (Yes/No) & $69 / 81$ & $70 / 80$ & 0.908 \\
\hline HP infection (Yes/No) & $31 / 59$ & $26 / 63$ & 0.453 \\
\hline Initial maximum diameter (mm) & $35.05 \pm 12.82$ & $36.13 \pm 13.63$ & 0.483 \\
\hline Perpendicular line of maximum diameter $(\mathrm{mm})$ & $26.82 \pm 10.57$ & $27.77 \pm 10.87$ & 0.442 \\
\hline Ulcer area $\left(\mathrm{mm}^{2}\right)$ & $1058.79 \pm 834.47$ & & 0.452 \\
\hline Postoperative bleeding: $\mathrm{n}$ & 10 & 6 & 0.304 \\
\hline
\end{tabular}

BMI, body mass index; HIN, high-grade intraepithelial neoplasia; HP, Helicobacter pylori; LIN, low-grade intraepithelial neoplasia.

\section{Table 2: Healing of ulcer post-ESD in the experimental and control groups}

\begin{tabular}{lccc}
\hline Factors & Control group $\boldsymbol{n}=\mathbf{1 3 3}$ & Experimental group $\boldsymbol{n}=\mathbf{1 3 7}$ & $\boldsymbol{P}$-value \\
\hline Ulcer maximum diameter, mm & & & \\
$\quad$ Initial & $34.57 \pm 12.43$ & $36.40 \pm 13.60$ & 0.250 \\
$\quad$ 4 weeks postoperatively & $7.80 \pm 5.96$ & $6.30 \pm 5.04$ & $0.027^{*}$ \\
Perpendicular line of maximum diameter, mm & & & 0.353 \\
$\quad$ Initial & $26.68 \pm 10.68$ & $27.88 \pm 10.61$ & $0.004^{*}$ \\
$\quad$ 4 weeks postoperatively & $4.75 \pm 3.64$ & $3.55 \pm 3.18$ & 0.325 \\
Ulcer area, mm ${ }^{2}$ & & & $0.011^{*}$ \\
$\quad$ Initial & $1033.52 \pm 840.04$ & $1133.90 \pm 832.61$ & $<0.001^{*}$ \\
$\quad$ 4 weeks postoperatively & $55.04 \pm 67.56$ & $36.35 \pm 51.36$ & 0.669 \\
Ulcer reduction rate at 4 weeks, \% & $0.94 \pm 0.078$ & $0.97 \pm 0.034$ & 0.109 \\
Ulcer healing rate at 4 weeks, \% & $27 / 133(20.3 \%)$ & $25 / 137(18.2 \%)$ & 1 \\
Ulcer improvement rate at 4 weeks, \% & $118 / 133(88.7 \%)$ & $129 / 137(94.2 \%)$ & $115 / 127(90.6 \%)$ \\
Ulcer reduction rate at 8 weeks, \% & $115 / 127(90.6 \%)$ & & \\
\hline
\end{tabular}

${ }^{*} P<0.05$, difference was statistically significant

subgroup analysis. Univariate analysis revealed that BMI $\left(\geq 23.22 \mathrm{~kg} / \mathrm{m}^{2}\right.$ vs. $<23.22 \mathrm{~kg} / \mathrm{m}^{2}$ ), lesion site (gastric antrum vs. others), patient sex, and the use of combination therapy (PPI + rebamipide vs. PPI monotherapy) were associated with ulcer reduction. Multivariate analysis indicated that combination therapy (PPI + rebamipide vs. PPI monotherapy) and lesion site (gastric antrum vs. others) were independent factors associated with greater 
post-ESD ulcer reduction. The adjusted odds ratios (ORs) were $4.31(2.51-7.39)$ and $0.47(0.28-0.80)$, respectively.

\section{Logistic regression analysis of factors influencing post-ESD ulcer healing}

Univariate and multivariate logistic regression models were used to analyze the factors affecting postESD ulcer healing at four weeks. The results are shown in Table 5. The dependent variable was post-ESD ulcer healing. The independent variables were the relevant variables determined by our subgroup analysis. Our univariate analysis revealed that pathological grade (cancer + HIN vs. LIN + others), initial ulcer area $\left(\geq 1084.45 \mathrm{~mm}^{2}\right.$ vs. $\left.<1084.45 \mathrm{~mm}^{2}\right)$, initial maximum diameter $(\geq 35.5 \mathrm{~mm}$ vs. $<35.5 \mathrm{~mm}$ ) and perpendicular diameter $(\geq 27.29 \mathrm{~mm}$ vs. $<27.29 \mathrm{~mm})$ were related to ulcer healing. The multivariate analysis indicated that pathological grade (cancer + HIN vs. LIN + others) and initial maximum diameter $(\geq 35.5 \mathrm{~mm}$ vs. $<35.5 \mathrm{~mm}$ ) were independent factors that influenced post-ESD ulcer reduction. The adjusted ORs were $0.33(0.17-0.62)$ and $0.36(0.17-0.75)$, respectively.

\section{Logistic regression analysis of factors influencing post-ESD ulcer improvement}

Univariate and multivariate logistic regression models were used to analyze the factors that affect post-ESD ulcer improvement at four weeks. The results are shown in Table 6 . The dependent variable was whether the post-ESD ulcer improved. The independent variables were the relevant variables determined by our subgroup analysis. Univariate analysis revealed that the initial ulcer area $\left(\geq 1084.45 \mathrm{~mm}^{2}\right.$

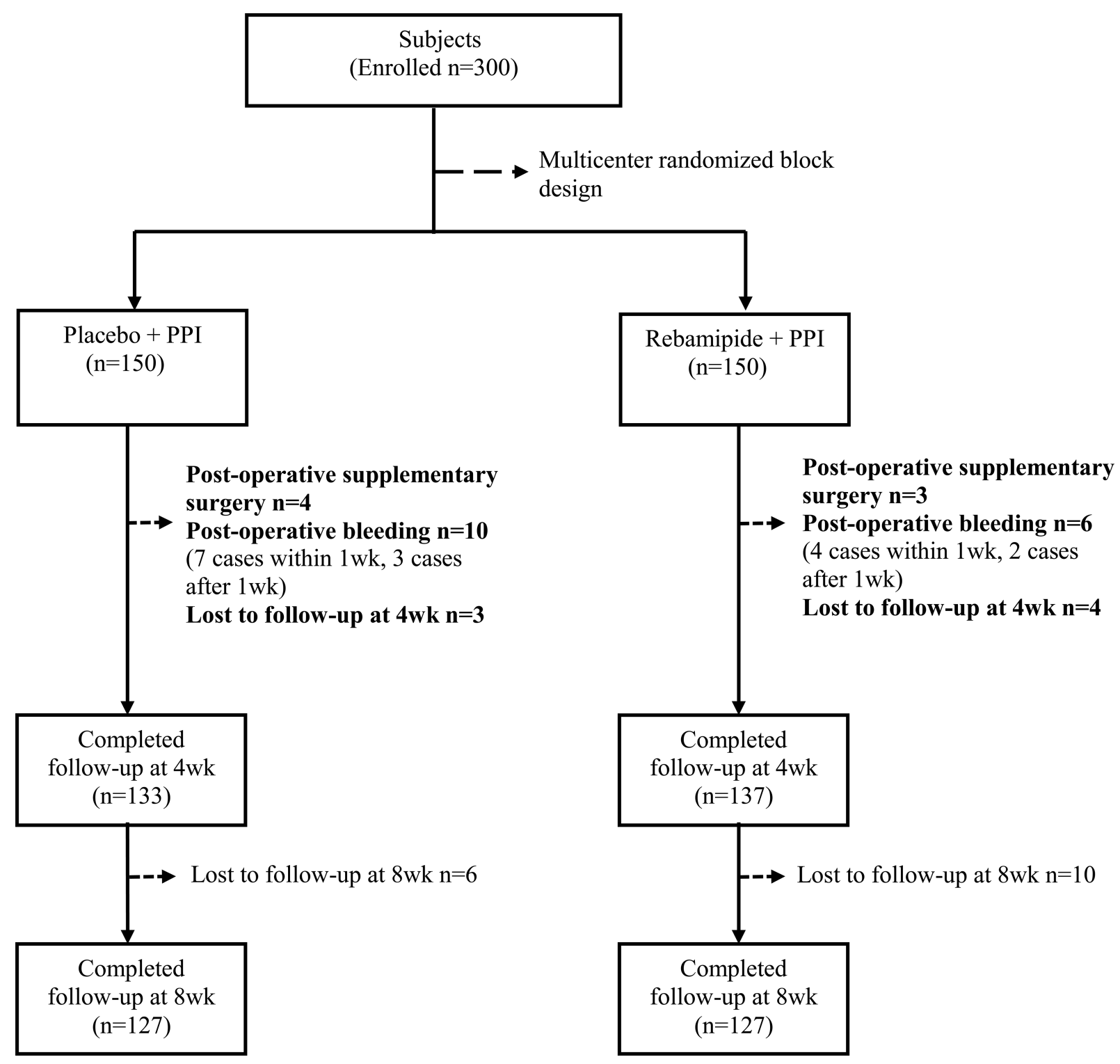

Figure 1: Flow chart of research procedure through the clinical trial. 
Table 3: Subgroup analysis of ulcer reduction post-ESD in the experimental and control groups

\begin{tabular}{|c|c|c|c|}
\hline Factors & $\begin{array}{c}\text { Control group } n=133 \\
\text { (Average reduction rate) }\end{array}$ & $\begin{array}{l}\text { Experimental group } n=137 \\
\text { (Average reduction rate) }\end{array}$ & $P$-value \\
\hline \multicolumn{4}{|c|}{ Initial maximum diameter, $\mathrm{mm}$} \\
\hline$<35.50$ & $79(93.4)$ & $79(97.6)$ & $<0.001^{*}$ \\
\hline$\geq 35.50$ & $54(94.7)$ & $58(96.3)$ & 0.065 \\
\hline \multicolumn{4}{|c|}{$\begin{array}{l}\text { Initial perpendicular line of maximum } \\
\text { diameter, } \mathrm{mm}\end{array}$} \\
\hline$<27.29$ & $75(92.6)$ & $76(97.3)$ & $<0.001^{*}$ \\
\hline$\geq 27.29$ & $58(95.6)$ & $61(96.7)$ & 0.116 \\
\hline \multicolumn{4}{|c|}{ Initial ulcer area, $\mathrm{mm}^{2}$} \\
\hline$<1084.45$ & $86(93.1)$ & $85(97.6)$ & $<0.001^{*}$ \\
\hline$\geq 1084.45$ & $47(95.5)$ & $52(96.2)$ & 0.373 \\
\hline \multicolumn{4}{|l|}{ Age, years } \\
\hline$<60$ & $66(93.4)$ & $64(97.4)$ & $0.003^{*}$ \\
\hline$\geq 60$ & $67(94.4)$ & $73(96.8)$ & $0.001^{*}$ \\
\hline \multicolumn{4}{|l|}{ BMI } \\
\hline$<23.22$ & $65(94.4)$ & $83(97.4)$ & $0.007^{*}$ \\
\hline$\geq 23.22$ & $68(93.5)$ & $54(96.5)$ & $0.003^{*}$ \\
\hline \multicolumn{4}{|l|}{ Lesion site } \\
\hline Gastric antrum & $66(94.3)$ & $72(97.6)$ & $0.002^{*}$ \\
\hline Others & $67(93.5)$ & $65(96.4)$ & $0.008^{*}$ \\
\hline \multicolumn{4}{|l|}{ Pathological grade } \\
\hline Cancer + HIN & $56(93.5)$ & $55(97.8)$ & $0.001^{*}$ \\
\hline LIN + others & $77(94.2)$ & $82(96.5)$ & $0.008^{*}$ \\
\hline \multicolumn{4}{|l|}{ Underlying disease } \\
\hline No & $60(93.1)$ & $64(97.6)$ & $<0.001^{*}$ \\
\hline Yes & $73(94.6)$ & $73(96.6)$ & $0.029^{*}$ \\
\hline HP infection & $n=81$ & $n=85$ & \\
\hline No & $54(93.1)$ & $61(96.8)$ & $0.007^{*}$ \\
\hline Yes & $27(92.2)$ & $24(97.5)$ & $0.003^{*}$ \\
\hline
\end{tabular}

${ }^{*} P<0.05$, difference was statistically significant; BMI, body mass index; HIN, high-grade intraepithelial neoplasia; Helicobacter pylori; LIN, low-grade intraepithelial neoplasia.

vs. $\left.<1084.45 \mathrm{~mm}^{2}\right)$, initial maximum diameter $(\geq 35.5$ $\mathrm{mm}$ vs. $<35.5 \mathrm{~mm})$ and perpendicular diameter $(\geq 27.29$ $\mathrm{mm}$ vs. $<27.29 \mathrm{~mm}$ ) were related to ulcer improvement. Multivariate analysis indicated the initial maximum diameter $(\geq 35.5$ vs. $<35.5)$ was an independent factor that influenced post-ESD ulcer reduction. The adjusted OR was $0.34(0.14-0.81, P=0.015)$.

\section{DISCUSSION}

The PPI treatment of eight weeks is the standard therapy for the common gastric ulcer. However, there is no standardized regimen for the treatment of gastric giant iatrogenic ulcers induced by ESD. Previous medical therapy contained the PPI alone, mucosa protectant alone, as well as the combination of these two drugs, and the course for the treatment is four to eight weeks. Previous studies showed that PPI alone or mucosa protectant alone for four weeks, the ulcer healing rate was $11.5 \%$ $36 \%$, however, the ulcer healing rate in the combination therapy group was $9.5 \%-68 \%[11,13,14]$, indicating that the combination therapy was better. In our study, we performed a large-scale, multicenter, prospective, randomized, double-blind, parallel-group, positivecontrolled trial to evaluate optimal treatment for post-ESD ulcer.

At four weeks, the ulcer improvement rates in the experimental and control groups were $94.2 \%$ and $88.7 \%$, respectively. However, the rates of ulcer area reduction were $0.97 \pm 0.034 \mathrm{~mm}^{2}$ and $0.94 \pm 0.078 \mathrm{~mm}^{2}$ 
Table 4: Logistic regression analysis of factors influencing ulcer reduction post-ESD

\begin{tabular}{|c|c|c|c|c|c|c|c|c|}
\hline \multirow{2}{*}{ Factors } & \multicolumn{5}{|c|}{ Univariate analysis $(n=270)$} & \multicolumn{3}{|c|}{$\begin{array}{l}\text { Multivariate analysis } \\
\qquad(n=270)\end{array}$} \\
\hline & $\begin{array}{c}\text { Ulcer reduction } \\
\text { rate }<95.5 \%\end{array}$ & $\begin{array}{l}\text { Ulcer reduction } \\
\text { rate } \geq 95.5 \%\end{array}$ & $P$-value & OR & $95 \% \mathrm{CI}$ & $P$-value & OR & $95 \%$ CI \\
\hline Age, $\geq 60 /<60$ & $58 / 44$ & $82 / 86$ & 0.199 & 0.72 & $0.44-1.19$ & & & \\
\hline HP infection, Yes/No & $25 / 45$ & $26 / 70$ & 0.234 & 0.67 & $0.34-1.30$ & & & \\
\hline Lesion site, Gastric antrum/ Others & $61 / 41$ & $71 / 97$ & $0.005^{*}$ & 0.49 & $0.30-0.81$ & $0.006^{*}$ & 0.47 & $0.28-0.80$ \\
\hline Pathological grade, Cancer + HIN/LIN + Others & $67 / 35$ & $92 / 76$ & 0.077 & 0.63 & $0.38-1.05$ & & & \\
\hline Initial maximum diameter, $\geq 35.5 /<35.5$ & $48 / 54$ & $64 / 104$ & 0.147 & 0.69 & $0.42-1.14$ & & & \\
\hline $\begin{array}{l}\text { Initial perpendicular line of maximum diameter, } \\
\geq 27.29 /<27.29\end{array}$ & $43 / 59$ & $76 / 92$ & 0.621 & 1.13 & $0.69-1.86$ & & & \\
\hline Initial ulcer area, $\geq 1084.45 /<1084.45$ & $42 / 60$ & $57 / 111$ & 0.231 & 0.73 & $0.44-1.22$ & & & \\
\hline Underlying disease, Yes/No & $56 / 46$ & $90 / 78$ & 0.832 & 0.95 & $0.58-1.55$ & & & \\
\hline Gender, Male/Female & $78 / 24$ & $109 / 59$ & $0.045^{*}$ & 1.76 & $1.01-3.07$ & & & \\
\hline$(\mathrm{PPI}+$ rebamipide)/PPI & $30 / 72$ & $107 / 61$ & $<0.001^{*}$ & 4.21 & $2.48-7.15$ & $<0.001^{*}$ & 4.31 & $2.51-7.39$ \\
\hline
\end{tabular}

${ }^{*} \mathrm{P}<0.05$, difference was statistically significant; CI, confidence interval; HIN, high-grade intraepithelial neoplasia; HP, Helicobacter pylori; LIN, low-grade intraepithelial neoplasia; OR, odds ratio; PPI, proton pump inhibitor; $n=270$ (excluding 30 patients lost to follow-up).

Table 5: Logistic regression analysis of factors influencing ulcer healing post-ESD

\begin{tabular}{|c|c|c|c|c|c|c|c|c|}
\hline \multirow{2}{*}{ Factors } & \multicolumn{5}{|c|}{ Univariate analysis $(n=270)$} & \multicolumn{3}{|c|}{ Multivariate analysis $(n=270)$} \\
\hline & Ulcer not healed & Ulcer healed & $P$-value & OR & $95 \%$ CI & $P$-value & OR & $95 \% \mathrm{CI}$ \\
\hline Age, $\geq 60 /<60$ & $119 / 99$ & $21 / 31$ & 0.066 & 0.56 & $0.31-1.04$ & & & \\
\hline BMI, $\geq 23.25 /<23.25$ & $100 / 118$ & $22 / 30$ & 0.643 & 0.87 & $0.47-1.60$ & & & \\
\hline HP infection, Yes/No & 46.95 & $5 / 20$ & 0.207 & 0.52 & $0.18-1.46$ & & & \\
\hline $\begin{array}{l}\text { Lesion site, Gastric antrum/ } \\
\text { Others }\end{array}$ & $111 / 107$ & $21 / 31$ & 0.172 & 0.65 & $0.35-1.21$ & & & \\
\hline $\begin{array}{l}\text { Pathological grade, Cancer }+ \\
\text { HIN/ LIN + Others }\end{array}$ & $141 / 77$ & $18 / 34$ & $\begin{array}{c}< \\
0.001^{*}\end{array}$ & 0.29 & $0.15-0.55$ & $0.001^{*}$ & 0.33 & $0.17-0.62$ \\
\hline $\begin{array}{l}\text { Initial maximum diameter, } \\
\geq 35.5 /<35.5\end{array}$ & $101 / 117$ & $11 / 41$ & $0.001^{*}$ & 0.31 & $0.15-0.64$ & $0.006^{*}$ & 0.36 & $0.17-0.75$ \\
\hline $\begin{array}{l}\text { Initial perpendicular line of } \\
\text { maximum diameter, } \geq 27.29 \text { / } \\
<27.29\end{array}$ & $10 / 115$ & $16 / 36$ & $0.032^{*}$ & 0.50 & $0.26-0.95$ & & & \\
\hline $\begin{array}{l}\text { Initial ulcer area, } \geq 1084.45 / \\
<1084.45\end{array}$ & $88 / 130$ & $11 / 41$ & $0.010^{*}$ & 0.40 & $0.19-0.81$ & & & \\
\hline Underlying disease, Yes/No & $113 / 105$ & $33 / 19$ & 0.131 & 1.61 & $0.87-3.01$ & & & \\
\hline Gender, Male/Female & $156 / 62$ & $31 / 21$ & 0.093 & 1.70 & $0.91-3.19$ & & & \\
\hline$(\mathrm{PPI}+$ rebamipide $) / \mathrm{PPI}$ & $112 / 106$ & $25 / 27$ & 0.669 & 0.88 & $0.48-1.61$ & & & \\
\hline
\end{tabular}

${ }^{*} P<0.05$, difference was statistically significant; BMI, body mass index; CI, confidence interval; ESD, endoscopic submucosal dissection; HIN, high-grade intraepithelial neoplasia; HP, Helicobacter pylori; LIN, low-grade intraepithelial neoplasia; OR, odds ratio; PPI, proton pump inhibitor; $n=270$ (excluding 30 patients lost to follow-up).

in the experimental and control groups respectively, and this difference between the two groups was statistically significant. Therefore, combination therapy promoted ulcer healing more successfully than monotherapy. This conclusion is consistent with the results of previous studies $[9-12,15,16]$. The ulcer healing at week 4 was less than $21 \%$, indicating that the course for therapy should be longer than 4 weeks. The ulcer healing rates for initial maximum diameter $\geq 35.5 \mathrm{~mm}$ and $<35.5 \mathrm{~mm}$ at week 8 were $84.6 \%$ and $94.7 \%(P<0.007)$, indicating that initial maximum diameter of ulcer is an important factor for healing of post-ESD ulcer and 8 weeks' treatment is recommended. Whether the conventional ulcer classification system proposed by Sakita et al. was suitable to be employed in this study needs discussion [17]. This classification system is a valuable guide for the clinical treatment and prognosis of ulcers, but it is not objective or continuous. Moreover, the distinction between A- and 
Table 6: Logistic regression analysis of factors influencing ulcer improvement post-ESD

\begin{tabular}{|c|c|c|c|c|c|c|c|c|}
\hline \multirow[b]{2}{*}{ Factors } & \multicolumn{5}{|c|}{ Univariate analysis $(n=270)$} & \multicolumn{3}{|c|}{ Multivariate analysis $(n=270)$} \\
\hline & $\begin{array}{l}\text { Ulcer not } \\
\text { improved }\end{array}$ & $\begin{array}{c}\text { Ulcer } \\
\text { improved }\end{array}$ & $P$-value & OR & $95 \%$ CI & $P$-value & OR & $95 \%$ CI \\
\hline Age, $\geq 60 /<60$ & $10 / 13$ & $130 / 117$ & 0.401 & 1.44 & $0.61-3.42$ & & & \\
\hline BMI, $\geq 23.25 /<23.25$ & $11 / 12$ & $111 / 136$ & 0.790 & 0.89 & $0.38-2.10$ & & & \\
\hline HP infection, Yes/No & $4 / 11$ & $47 / 104$ & 0.721 & 1.24 & $0.38-4.11$ & & & \\
\hline Lesion site, Gastric antrum/ Others & $14 / 9$ & $118 / 129$ & 0.229 & 0.59 & $0.25-1.41$ & & & \\
\hline $\begin{array}{l}\text { Pathological grade, Cancer + HIN/ } \\
\text { LIN + Others }\end{array}$ & $16 / 7$ & $143 / 104$ & 0.277 & 0.60 & $0.24-1.52$ & & & \\
\hline $\begin{array}{l}\text { Initial maximum diameter, } \\
\geq 35.5 /<35.5\end{array}$ & $15 / 8$ & $97 / 150$ & $0.016^{*}$ & 0.35 & $0.14-0.84$ & $0.015^{*}$ & 0.34 & $0.14-0.81$ \\
\hline $\begin{array}{l}\text { Initial perpendicular line } \\
\text { of maximum diameter, } \\
\geq 27.29 /<27.29\end{array}$ & $15 / 8$ & $104 / 143$ & $0.033^{*}$ & 0.39 & $0.16-0.95$ & & & \\
\hline $\begin{array}{l}\text { Initial ulcer area, } \\
\geq 1084.45 /<1084.45\end{array}$ & $14 / 9$ & $85 / 162$ & $0.012^{*}$ & 0.34 & $0.14-0.81$ & & & \\
\hline Underlying disease, Yes/No & $12 / 11$ & $134 / 113$ & 0.848 & 1.09 & $0.46-2.56$ & & & \\
\hline Gender, Male/Female & $19 / 4$ & $168 / 79$ & 0.147 & 2.23 & $0.74-6.78$ & & & \\
\hline$(\mathrm{PPI}+$ rebamipide $) / \mathrm{PPI}$ & $8 / 15$ & $129 / 118$ & 0.109 & 2.05 & $0.84-5.01$ & & & \\
\hline
\end{tabular}

${ }^{*} P<0.05$, difference was statistically significant; BMI, body mass index; CI, confidence interval; ESD, endoscopic submucosal dissection; HP, HIN, high-grade intraepithelial neoplasia; Helicobacter pylori; LIN, low-grade intraepithelial neoplasia; OR, odds ratio; PPI, proton pump inhibitor; $n=270$ (excluding 30 patients lost to follow-up).

$\mathrm{H}$-stage ulcers is not clear. Therefore, a new method is required to improve the evaluation of post-ESD ulcers, particularly giant iatrogenic ulcers.

Numerous factors may influence post-ESD ulcer healing, including ulcer area, ulcer site, pathological grade, blood coagulation status, Hp infection and other comorbidities. However, studies investigating post-ESD ulcer healing have not achieved consensus regarding the importance of these factors. Our study showed that the combination therapy and lesions located in the gastric antrum were both positively associated with the ulcer healing. Oh, et al. [18] showed that the degree of ulcer healing within four weeks was determined by the initial size of the ulcer. Similarly, Nakamura, et al. also suggested that the initial size of the ulcer and the location of lesion could affect healing of post-ESD ulcer [14], which supports our results. Therefore, the longer course of treatment should be taken for the bigger initial size of the post-ESD ulcer.

The most significant complication that occurs during post-ESD ulcer healing is bleeding. In our study, the overall incidence of bleeding was $5.33 \%$, which was far lower than the results reported in the foreign literature (13\%-38\%) [19]. The most likely explanation for this is the significant reduction in the incidence of bleeding that has occurred in recent years as endoscopy instruments have improved allowing the coagulation of blood vessels using hot biopsy forceps. In this study, the overall incidences of bleeding in control and experimental groups were $7.14 \%$ and $4.17 \%$ with no significant difference.

The reasons for choosing to evaluate rebamipide and the PPI lansoprazole were as follows. First, antacids are still the most effective treatment for post-ESD ulcers [20], and several studies have shown that the clinical efficacy of PPIs is superior to that of H2RAs [21, 22]. Second, PPIs combined with a mucosal protective agent is better able to promote ulcer healing compared to PPI monotherapy $[9-12,15,16]$. A meta-analysis that included 11 randomized controlled trials indicated that the clinical efficacy of combination therapy is superior to PPI monotherapy [15]. Finally, rebamipide has more significant effects on the healing of post-ESD ulcers than other mucosal protective agents [15]. It may act by promoting the expression of gastric mucosal protective factors (PGE-R and COX-2), promoting the synthesis of various growth factors (epidermal growth factor [EGF], EGF receptor and vascular endothelial growth factor), inhibiting gastric mucosal injury factors, inhibiting Hp adherence to endothelial cells, inhibiting the production of IL-8/LT-B4, or inhibiting the expression of adhesion molecules CD11b/CD18 and ICAM-1 [8, 23, 24].

In the preliminary stages of this trial, we tested three methods for ulcer diameter measurement: Direct measurement through the endoscope biopsy channel using an endoscopic measuring instrument (Olympus Corp., Tokyo, Japan); Measurement by comparison with a visual reference (a paper disk) using Amedicom System image analysis software for image distance measurements; Direct measurement of the post-ESD specimens. Similar studies from abroad commonly apply the first method of measurement [16]. However, during the resection operation, the large size of the post-ESD ulcers made it difficult to visualize them within a single field. Moreover, the ulcers were not located in the same plane. Hence, the first two 
methods lacked the accuracy required for the measurement of such ulcers. Therefore, we chose to use the resected specimen measurement as a surrogate for the measurement of the corresponding post-ESD ulcer. However, due to the drastically reduced sizes of the ulcers four and eight weeks postoperatively, we were able to employ the second method and obtain relatively accurate measurements.

In conclusion, both the PPI monotherapy and the PPI plus rebamipide treatments ended up with low post-ESD ulcer healing rates in the first four weeks of postoperative treatment. After eight weeks of treatment, over $90 \%$ of ulcers were in the healing or scarring stage. Compared with lansoprazole alone, rebamipide combined with lansoprazole significantly accelerated the rate of ulcer reduction but did not improve the rate of ulcer healing at four weeks of therapy.

\section{MATERIALS AND METHODS}

\section{Experimental design}

We performed a multicenter, prospective, randomized, double-blind, parallel-group, positive-controlled trial at six participating medical institutions (all AAA hospitals). The study was approved by the Ethical Review Committee of the Chinese PLA General Hospital and entered in the Chinese Clinical Trial Registry (registration number, ChiCTR-TRC-13003032). Each center recruited 50 patients (300 patients in total) admitted between May 2013 and December 2014. Patients were recruited if they had one of the following indications for ESD: 1. a gastric adenoma with low- to high-grade intraepithelial neoplasia (LIN and HIN, respectively) that was difficult to remove using conventional methods (e.g. endoscopic mucosal resection $[\mathrm{EMR}])$; 2. a well-differentiated or moderately differentiated intramucosal carcinoma; 3. a welldifferentiated or moderately differentiated superficial gastric carcinoma (invasion depth $<500 \mu \mathrm{m}$, and, in the presence of ulcers, $<3 \mathrm{~cm}) ; 4$. an undifferentiated carcinoma $<2$ $\mathrm{cm}$, without ulceration. All diagnoses were confirmed by gastroscopy and histopathology. Additional inclusion criteria included: 1 . age 18-80 years, 2. absence of major cardiopulmonary disease and no history of hepatobiliary or other gastrointestinal disease or surgery, 3. normal blood coagulation, and 4. no use of antacids or mucosal protective agents within two weeks of enrollment. We excluded patients: 1. who required additional anti-ulcer medications after enrollment, 2. who were pregnant, breastfeeding, or might become pregnant during the trial period, and 3 . with severe intraoperative complications requiring surgical treatment. All patients voluntarily participated in the study and gave informed consent.

\section{ESD operation procedures}

Enrolled patients $(n=300)$ underwent endoscopic examinations and ESD procedures performed by experts with much experience in ESD. The margin of resection was marked using electrocoagulation and included approximately $0.5 \mathrm{~cm}$ of normal mucosal tissue around the lesion. We injected liquid into the submucosa to lift the lesion and separate the submucosa from the muscular layer. The mucosa and submucosa on the outer edge of the lesion were incised along the previously marked margin. Then, the submucosa was dissected until the mucosal lesion had been completely resected. Electrocoagulation was applied to exposed blood vessels in the wound. The resected specimen was sent for pathologic examination. The measurements of the resected lesion and surgical wound were recorded.

\section{Patient grouping and drug administration}

Enrolled patients were randomly assigned to the experimental group $(n=150)$ or the control group $(n=150)$. Patients in the control group received intravenous pantoprazole (30 mg every 12 hours; Nycomed Pharmaceutical Consultancy Co., Ltd., Shanghai, China) and a placebo (three times daily) on postoperative days $1-3$. On postoperative days 4-56 they received oral lansoprazole (disintegrating tablets, $30 \mathrm{mg}$ daily; Tianjin Takeda Pharmaceutical Co., Ltd., Tianjin, China) and placebo (three times daily). Patients in the experimental group received intravenous pantoprazole (30 mg every 12 hours) and oral rebamipide (100 mg three times daily; Zhejiang Yuan Li Jian Pharmaceutical Co., Ltd., Hangzhou, China) on postoperative days $1-3$. On postoperative days 4-56 they received oral lansoprazole (disintegrating tablets, $30 \mathrm{mg}$ daily) and rebamipide (100 $\mathrm{mg}$ three times daily). Concurrent use of the following drugs was prohibited during the trial period: other PPIs, $\mathrm{H}_{2}$-receptor antagonists (H2RA), and gastric mucosal protective agents, as well as non-steroidal antiinflammatory drugs, anticoagulants, and antiplatelet drugs.

\section{Specimen measurement and surgical site evaluations}

\section{Endoscopic measurement of ulcer size}

The resected specimen was spread out in vitro and fixed in place using pins. Calipers were used to directly measure the maximum diameter and the perpendicular line of the maximum diameter.

\section{Endoscopic follow-up evaluations}

Enrolled patients underwent follow-up endoscopy at four and eight weeks postoperatively to evaluate ulcer healing. Four weeks postoperatively, a five mm-diameter white paper disk (produced using a hole puncher) was positioned at the edge of the ulcer site using biopsy forceps placed through the endoscope biopsy channel. The ulcers were photographed using the paper disk as a 
reference. The photographic images were uploaded to a computer and measured using the Amedicom software system. The maximum diameter and perpendicular line of the maximum diameter were recorded (Supplementary Figure 1).

\section{Ulcer size and rate of reduction}

The ulcer size and rate of reduction were calculated based as follows: Ulcer area $=$ ulcer maximum diameter $\times$ perpendicular line of maximum diameter $\left(\mathrm{mm}^{2}\right)$. Ulcer reduction rate at four weeks $=$ (initial ulcer area ulcer area at four weeks) $\times 100 /$ initial ulcer area. Ulcer reduction rate at eight weeks $=($ initial ulcer area - ulcer area at eight weeks) $\times 100 /$ initial ulcer area.

\section{Endoscopic ulcer classification and healing evaluation}

We staged each ulcer according to the classification system developed by Sakita et al. [17]. Based on the endoscopic presentations, the ulcers were classified into six stages: active (A1 and A2), healing ( $\mathrm{H} 1$ and $\mathrm{H} 2$ ), and scarring ( $\mathrm{S} 1$ and $\mathrm{S} 2)$. We classified treatment as effective (H-stage ulcers with $\geq 50 \%$ reduction in maximum diameter and S-stage ulcers) or not effective (H-stages ulcers with $<50 \%$ reduction in maximum diameter and A-stage ulcers). The ulcer healing rate was calculated as the number of S-stage ulcers/total number of cases $\times 100 \%$. The ulcer improvement rate was calculated as the number of effective cases/total number of cases $\times 100 \%$. A team of five endoscopic experts blinded to patient groups performed the endoscopic staging of ulcer healing. The healing stages were assigned based on the consensus of three or more evaluators.

\section{Statistical analysis}

Independent third-parties were responsible for performing the statistical analyses, participating in the experimental design and implementation, conducting sample blinding, managing the data, and completing the summary statistical report. SPSS for Windows, Version 13.0 (SPSS Inc., Chicago, IL, US) was employed for our statistical analyses. Quantitative variables were analyzed using the Wilcoxon signedrank or Student's $t$-test and are reported as mean \pm standard deviations. Categorical variables were analyzed using the Pearson chi-squared test and are reported as the number of cases and percentages. All statistical analyses were two-tailed tests and a $P$-value $<0.05$ was considered statistically significant. Logistic regression analyses were performed to analyze factors influencing post-ESD ulcer reduction, ulcer healing and ulcer improvement, respectively.

\section{Author contributions}

Yang YS designed research; Lu ZS, Ge ZZ, Liu SD, Guo XG, Tian DA, Yang YX, Li XB, Gong W, Liu ZG, Liu M, Zhou BX, Zhao KB and Yang J performed research; Yan B analyzed data; Yan B wrote the paper.

\section{CONFLICTS OF INTEREST}

The authors declare no conflicts of interest.

\section{GRANT SUPPORT}

Nursery science and technology innovation fund of Chinese PLA General Hospital, NO: 13KMM02.

\section{REFERENCES}

1. Gotoda T, Kondo H, Ono H, Saito Y, Yamaguchi H, Saito D, Yokota T. A new endoscopic mucosal resection procedure using an insulation-tipped electrosurgical knife for rectal flat lesions: report of two cases. Gastrointest Endosc. 1999; 50:560-563.

2. Ono H, Kondo H, Gotoda T, Shirao K, Yamaguchi H, Saito D, Hosokawa K, Shimoda T, Yoshida S. Endoscopic mucosal resection for treatment of early gastric cancer. Gut. 2001; 48:225-229.

3. Isomoto H, Shikuwa S, Yamaguchi N, Fukuda E, Ikeda K, Nishiyama H, Ohnita K, Mizuta Y, Shiozawa J, Kohno S. Endoscopic submucosal dissection for early gastric cancer: a large-scale feasibility study. Gut. 2009; 58:331-336.

4. Kakushima N, Fujishiro M, Kodashima S, Kobayashi K, Tateishi A, Iguchi M, Imagawa A, Motoi T, Yahagi N, Omata M. Histopathologic characteristics of gastric ulcers created by endoscopic submucosal dissection. Endoscopy. 2006; 38:412-415.

5. Kakushima N, Fujishiro M, Yahagi N, Kodashima S, Nakamura M, Omata M. Helicobacter pylori status and the extent of gastric atrophy do not affect ulcer healing after endoscopic submucosal dissection. J Gastroenterol Hepatol. 2006; 21:1586-1589.

6. Kakushima N, Tanaka M, Sawai H, Imai K, Kawata N, Hagiwara T, Takao T, Hotta K, Yamaguchi Y, Takizawa K, Matsubayashi H, Ono H. Gastric obstruction after endoscopic submucosal dissection. United European Gastroenterol J. 2013; 1:184-190.

7. Nonaka K, Miyazawa M, Ban S, Aikawa M, Akimoto N, Koyama I, Kita H. Different healing process of esophageal large mucosal defects by endoscopic mucosal dissection between with and without steroid injection in an animal model. BMC Gastroenterol. 2013; 13:72.

8. Arakawa T, Higuchi K, Fujiwara Y, Watanabe T, Tominaga K, Sasaki E, Oshitani N, Yoshikawa T, Tarnawski AS. 15 th anniversary of rebamipide: looking ahead to the new 
mechanisms and new applications. Dig Dis Sci. 2005; 50:S3-S11.

9. Takayama M, Matsui S, Kawasaki M, Asakuma Y, Sakurai T, Kashida H, Kudo M. Efficacy of treatment with rebamipide for endoscopic submucosal dissection-induced ulcers. World J Gastroenterol. 2013; 19:5706-5712.

10. Fujiwara S, Morita Y, Toyonaga T, Kawakami F, Itoh T, Yoshida M, Kutsumi H, Azuma T. A randomized controlled trial of rebamipide plus rabeprazole for the healing of artificial ulcers after endoscopic submucosal dissection. J Gastroenterol. 2011; 46:595-602.

11. Kato T, Araki H, Onogi F, Ibuka T, Sugiyama A, Tomita E, Nagaki M, Moriwaki H. Clinical trial: rebamipide promotes gastric ulcer healing by proton pump inhibitor after endoscopic submucosal dissection--a randomized controlled study. J Gastroenterol. 2010; 45:285-290.

12. Kobayashi M, Takeuchi M, Hashimoto S, Mizuno K, Sato Y, Narisawa R, Aoyagi Y. Contributing factors to gastric ulcer healing after endoscopic submucosal dissection including the promoting effect of rebamipide. Dig Dis Sci. 2012; 57:119-126.

13. Asakuma Y, Kudo M, Matsui S, Okada M, Kawasaki M, Umehara Y, Ichikawa T, Kitai S. Comparison of an ecabet sodium and proton pump inhibitor (PPI) combination therapy with PPI alone in the treatment of endoscopic submucosal dissection (ESD) - induced ulcers in early gastric cancer: prospective randomized study. Hepatogastroenterology. 2009; 56:1270-1273.

14. Nakamura K, Ihara E, Akiho H, Akahoshi K, Harada N, Ochiai T, Nakamura N, Ogino H, Iwasa T, Aso A, Iboshi Y, Takayanagi R. Limited Effect of Rebamipide in Addition to Proton Pump Inhibitor (PPI) in the Treatment of Post-Endoscopic Submucosal Dissection Gastric Ulcers: A Randomized Controlled Trial Comparing PPI Plus Rebamipide Combination Therapy with PPI Monotherapy. Gut Liver. 2016; 10:917-924.

15. Nishizawa T, Suzuki H, Kanai T, Yahagi N. Proton pump inhibitor alone vs proton pump inhibitor plus mucosal protective agents for endoscopic submucosal dissectioninduced ulcer: a systematic review and meta-analysis. J Clin Biochem Nutr. 2015; 56:85-90.

16. Shin WG, Kim SJ, Choi MH, Kim KO, Jang HJ, Park CH, Baek IH, Kim KH, Baik GH, Kae SH, Kim JH, Kim HY.
Can rebamipide and proton pump inhibitor combination therapy promote the healing of endoscopic submucosal dissection-induced ulcers? A randomized, prospective, multicenter study. Gastrointest Endosc. 2012; 75:739747.

17. Sakita T. [Endoscopic diagnosis of gastric cancer]. [Article in Japanese]. Gan norinsho. 1972. Suppl:108-114.

18. Oh TH, Jung HY, Choi KD, Lee GH, Song HJ, Choi KS, Chung JW, Byeon JS, Myung SJ, Yang SK, Kim JH. Degree of healing and healing-associated factors of endoscopic submucosal dissection-induced ulcers after pantoprazole therapy for 4 weeks. Dig Dis Sci. 2009; 54:1494-1499.

19. Yamamoto H, Sekine Y, Higashizawa T, Kihira K, Kaneko Y, Hosoya Y, Ido K, Saito K, Sugano K. Successful en bloc resection of a large superficial gastric cancer by using sodium hyaluronate and electrocautery incision forceps. Gastrointest Endosc. 2001; 54:629-632.

20. Fujishiro M, Chiu PW, Wang HP. Role of antisecretory agents for gastric endoscopic submucosal dissection. Dig Endosc. 2013; 25:86-93.

21. Uedo N, Takeuchi Y, Yamada T, Ishihara R, Ogiyama H, Yamamoto S, Kato M, Tatsumi K, Masuda E, Tamai C, Yamamoto S, Higashino K, Iishi H, Tatsuta M. Effect of a proton pump inhibitor or an H2-receptor antagonist on prevention of bleeding from ulcer after endoscopic submucosal dissection of early gastric cancer: a prospective randomized controlled trial. Am J Gastroenterol. 2007; 102:1610-1616.

22. Yang Z, Wu Q, Liu Z, Wu K, Fan D. Proton pump inhibitors versus histamine-2-receptor antagonists for the management of iatrogenic gastric ulcer after endoscopic mucosal resection or endoscopic submucosal dissection: a metaanalysis of randomized trials. Digestion. 2011; 84:315-320.

23. Arakawa T, Kobayashi K, Yoshikawa T, Tarnawski A. Rebamipide: overview of its mechanisms of action and efficacy in mucosal protection and ulcer healing. Dig Dis Sci. 1998; 43:5S-13S.

24. Tarnawski AS, Chai J, Pai R, Chiou SK. Rebamipide activates genes encoding angiogenic growth factors and Cox2 and stimulates angiogenesis: a key to its ulcer healing action? Dig Dis Sci. 2004; 49:202-209. 